\title{
The price of working abroad: Well-being among immigrant and native workers
}

El precio de trabajar en el extranjero: Bienestar en trabajadores inmigrantes y nativos

\author{
Pedro José Ramos Villagrasa ${ }^{\mathrm{A}}$ \\ pjramos@unizar.es
}

${ }^{\text {A} F a c u l t a d ~ d e ~ C i e n c i a s ~ S o c i a l e s ~ y ~ d e l ~ T r a b a j o, ~ U n i v e r s i d a d ~ d e ~ Z a r a g o z a ~}$

Calle Violante de Hungría, 23, despacho 35. 50017 Zaragoza.

\author{
Antonio León García Izquierdo ${ }^{B}$ \\ angarcia@uniovi.es \\ ${ }^{\text {B}}$ Facultad de Psicología, Universidad de Oviedo \\ Plaza Feijóo s/n, despacho 314. 33009 Oviedo.
}

Correspondence autor:

Pedro José Ramos Villagrasa

Funding:

This work was supported by Cátedra Asturias Prevención [ref. CAT-005-17]. 
Background. The merging of cultures has led to a more diverse workforce in organizations which has implications that should be taken into account, especially regarding occupational health. Studies undertaken worldwide have found that immigrant workers are subject to less well-being than their native counterparts. Very little is known about the determinants of those differences at the individual level. The present study explores the prediction of psychological health as a function of the origin of the worker (immigrant vs. native) with the 'Big Five' personality traits and the perception of safety climate as predictors. Method. Three hundred and ten workers (42.6\% immigrants, $57.4 \%$ natives) participated in the study. Predictors, criterion, and biographical variables were assessed by means of a self-administrated questionnaire. Multiple regression models were subsequently performed. Findings. We found no relevant differences between immigrants and natives in well-being, but there were differences in the predictors. Immigrants' well-being $\left(R^{2}{ }_{\text {adj }}=.23\right)$ was explained mainly by emotional stability $(\beta=.41, p=.000)$ and extraversion $(\beta=.22, p=.004)$, whereas natives' well-being $\left(R_{\text {adj }}^{2}=.37\right)$ was determined only by emotional stability $(\beta=.35, p=$ .000). Perception of safety climate was not involved in any model. Conclusions. The differential profile between immigrant and native workers provides support to the consideration of immigration as a risk factor, recommending the organizations to develop action plans to facilitate the acculturative process.

Keywords: immigrant workers; native workers; well-being; migrant personality; perception of safety climate; immigration. 
Antecedentes y objetivo. La fusión de culturas ha llevado a una fuerza de trabajo más diversa en las organizaciones, lo que tiene implicaciones para la salud en el trabajo. Estudios realizados en diferentes países han encontrado que los trabajadores inmigrantes están sujetos a menos bienestar que sus equivalentes nativos. Se sabe muy poco sobre los determinantes de esas diferencias a nivel individual. El presente estudio explora la predicción del bienestar psicológico según el origen del trabajador (inmigrante vs. nativo) usando los "Cinco Grandes" y la percepción del clima de seguridad como predictores. Materiales y métodos. Trescientos diez trabajadores (43.58\% inmigrantes, $57.42 \%$ nativos) participaron en el estudio. Las variables de interés se evaluaron mediante un cuestionario autoadministrado, para después realizar estadísticos descriptivos y modelos de regresión múltiple. Resultados. Aunque no se encuentran diferencias en el bienestar de inmigrantes y nativos, sí las hay en sus predictores. Así, el bienestar de los inmigrantes $\left(R_{\text {adj }}^{2}=, .23\right)$ tiene como predictores la estabilidad emocional $(\beta=, 41, p=.000)$ y la extraversión $(\beta=.22, p=.004)$, pero en el caso de los nacionales el bienestar $\left(R^{2}{ }_{\text {adj }}=\right.$ '37) tiene solamente la estabilidad emocional como predictor $(\beta=, .35, p=. .000)$. La percepción de clima de seguridad no participa en los modelos predictivos. Conclusiones. Los resultados apoyan la propuesta de considerar ser inmigrante como un factor de riesgo en la prevención de riesgos laborales, promoviendo que las organizaciones desarrollen planes de acción para facilitar la adaptación a la cultura de acogida.

Palabras clave: trabajadores inmigrantes; trabajadores nativos; personalidad migrante; percepción de clima de seguridad; inmigración. 
We live in a globalized era where the substantial growth of migratory movements increases diversity in organizations. The immigrant workforce presents differences in terms of personality, culture, values, etc. that should be considered by managers, as in the case of workplace safety (Janssens, Brett, \& Smith, 1995). This turns the study of the immigrant workforce and its dissimilarities with natives into an emergent trend. In that sense, studies developed all over the world across different jobs and cultures have revealed that immigrant workers report less well-being than their native counterparts (e.g., Dalgard, Thapa, Hauff, McCubbin, \& Syed, 2006; Hoppe, 2011). The main explanation for this is based on the fact that immigrants usually have a more precarious job status than natives (Schenker, 2010). Even when acknowledging that some organizations may ignore labor laws and occupational safety standards when hiring immigrants, this explanation assumes that the differences proceed from the job setting, and not from the workers' personal characteristics. This idea clashes with principal psychological research, which points out the relevance of individual factors like personality as a predictor of safety outcomes (Christian, Bradley, Wallace, \& Burke, 2009). Taking all of this into account, the present paper explores differences in the prediction of well-being based on the worker's origin (immigrant vs. native) using two individual-level variables that have been well supported by previous literature (personality and perception of safety climate). The findings of our study may help organizations with a diverse workforce to design successful safety interventions within an inclusive management policy.

\section{Immigration, well-being, and work}


Immigration implies an effort to successfully adapt to a different cultural context. First-generation immigrants (i.e., those who initially came to a host country) must face a process of adaptation (psychological acculturation; Berry, 1997), which comprises all life contexts and influences the immigrants' well-being. Well-being could be seen as an individual perception of satisfaction and fulfillment in all life domains, including work (Diener, Oishi, \& Lucas, 2003). The absence of well-being has negative consequences, including physical and psychosocial dimensions such as headaches, insomnia, depression, etc. Immigrants' well-being and work are intrinsically related: work is one of their major stressors (Yakhnich, 2008) and, at the same time, a capital source of their well-being (Vallejo-Martín \& Moreno-Jiménez, 2014).

Despite its relevance and the fact that they are two of the most studied variables in immigration research, work and well-being are not usually investigated simultaneously (cfr. Bennett, Scornaiencki, Brzozowski, Denis, \& Magalhaes, 2012). Previous research suggests that immigrants report worse well-being than natives, indicating external conditions as the explanation of the differences (e.g., Dalgard et al., 2006; Hoppe, 2011). However, external conditions scarcely account for the variance of well-being in comparison to endogenous factors (Diener et al., 2003). Among several endogenous predictors of well-being, we focus on distal predictors. Distal predictors (e.g., personality, safety climate) show a lower relationship with well-being than proximal predictors (e.g., task knowledge, communication), but they also have a stronger impact and are involved in more situations than proximal predictors. In the present study, we focus on a person-related factor (i.e., personality) and a situationalrelated factor (i.e., perception of safety climate).

The most widely accepted framework to describe personality at the workplace is the 'Big Five' factor model (i.e. emotional stability, extraversion, openness to 
experience, agreeableness, and conscientiousness), which is also supported by a considerable amount of evidence about its universality across cultures (McCrae \& Terracciano, 2005). Meta-analytic studies developed with general population showed that all 'Big Five' personality traits were positively related to well-being (e.g., Steel, Schmidt, \& Shultz, 2008). Thus, our first hypothesis is as follows:

H1: All the 'Big Five' personality traits will be positively associated with well-being.

However, Boneva and Frieze (2001) proposed that migrants share a set of characteristics (i.e., high work-orientation, high achievement and power motivation, lower affiliation motivation, and lower family centration), that differentiate them from those individuals who do not want to leave their home country labeling this profile as migrant personality. These characteristics are described by Tabor, Milfont, and Waard (2015) in terms of the 'Big Five' personality traits as high conscientiousness and high openness to experience. As empirical research found support for the migrant personality (e.g., Polek, Van Oudenhoven, \& Ten Berge, 2011), we expect that we will find similar results in our sample and will be able to explore its implications. Therefore, it seems reasonable that the differential profile of immigrants explains differences in outcomes such as well-being. Thus, our second hypothesis is:

H2: 'Big Five' traits will display the same direction but a different strength in the prediction of well-being depending on the origin of the worker (i.e., immigrant vs. native).

The other predictor is the perception of safety climate, a construct coined by Zohar (1980), which refers to "a summary of molar perceptions that employees share about their work environment" (p. 96). Like other constructs based on shared 
perceptions, safety climate has a multilevel nature that can be analyzed at the team level or at the individual-level. The longitudinal study that Dollard and Bakker (2010) carried out showed that safety climate is a distal determinant of well-being, which has been confirmed in later research (e.g., Idris, Dollard, Coward, \& Dormann, 2012). Thus, our third hypothesis is as follows:

H3: Perception of safety climate will be negatively associated with well-being.

Although studies examining safety climate and immigrant workers are scarce, the study performed by Guldenmund, Cleal, and Mearns (2013) has shown that immigrants working in three European countries (Denmark, United Kingdom, and the Netherlands) are a vulnerable group. According to Guldenmund et al., this is because of: (1) difficulties in understanding safety instructions, (2) some organizations have inadequate safety resources (e.g., safety instructions only available in the local language or insufficient checks in place to assess whether a newcomer has understood the instructions); (3) a significant proportion of immigrants are not officially registered, which implies a greater difficulty to control their safety at work. In our opinion, the aforementioned reasons lead to difficulties in immigrants' access to safety information, which, in turn, decreases the impact of the perception of safety climate on well-being. Thus, our last hypothesis is as follows:

H4: Perception of safety climate will present a lower relationship with the well-being of immigrant workers than with that of the natives.

\section{Method}




\section{Participants}

Three hundred and ten workers residing in the north of Spain participated in the study, of whom $132(42.6 \%)$ were immigrants, and $178(57.4 \%)$ were native. The sample was incidental.

Immigrant workers (56.1\% women, $43.9 \%$ men) were first-generation immigrants who come mainly from Latin America (72.7\%), while the other immigrants were divided among non-communitarian Europeans (14.4\%), Africans (6.1\%), and other cultures from all over the world (6.8\%). Their motivation to migrate was mainly economic needs ( $20.3 \%$ of the women and $33.5 \%$ of the men) and family reunification ( $18.1 \%$ of the women and $16.0 \%$ of the men). The mean period living in Spain is 59.06 months, although with a high variability $(S D=48.90)$. Most of the immigrants have a residence permit or are involved in the process of obtaining it $(59.6 \%$ of the women and $75.9 \%$ of the men). The mean age is $36.10(S D=9.98)$, and the mean amount of schooling is 12.22 years $(S D=4.64)$, with no sex differences. In terms of work, jobs in the service sector predominate $(72.7 \%)$, followed by the construction sector $(14.6 \%)$, industry $(6.5 \%)$, and lastly, agriculture and fishing $(0.8 \%)$. However, if we take sex into account, clear differences in jobs can be found: women work mostly in services $(94.4 \%$ vs. $55.8 \%$ of the men), followed by industry ( $4.2 \%$ vs. $9.6 \%$, for women and men, respectively), and construction ( $1.4 \%$ vs. $32.7 \%$ for women and men, respectively). Only men worked in agriculture and fishing (1.9\% of total male immigrants in our study).

Regarding the native workers ( $58.5 \%$ women, $41.5 \%$ men), their mean age is $27.03(S D=9.42)$, and the mean amount of schooling is 15.71 years $(S D=5.00)$. Natives also worked mainly in the services sector (69.1\%), followed by construction $(21.0 \%)$, and industry $(9.9 \%)$. Grouping according to sex, women worked mostly in 
services $(83.3 \%$ vs. $48.4 \%$ of the men), followed by construction $(14.6 \%$ vs. $31.3 \%$ of the men) and industry ( $2.1 \%$ vs. $20.3 \%$ of the men).

\section{Instruments}

This study was conducted by means of a simple retrospective cross-sectional design using a self-report survey with a set of scales to measure the variables of interest. All the tests have a 5-point Likert-type scale response format, ranging from (1) totally disagree to (5) totally agree. The questionnaire used in the present research has two different versions, one for immigrants and one for natives. Both versions are in Spanish and their only difference is that the immigrant version asks about the country of origin, time living in Spain, and legal status. As all immigrant participants could read and speak Spanish fluently, no changes were made in the instruments. However, as we detail in the procedure section, a member of the research team was available to solve doubts regarding the questionnaire, if necessary.

Spanish version of the Big Five Inventory (Benet-Martínez \& John, 1998) was used. Although the Spanish translation tends to have lower reliability indexes (e.g., Ramos-Villagrasa, García-Izquierdo, \& Navarro, 2013), it is considered a useful instrument to perform cross-cultural research (Schmitt, Allik, McCrae, \& BenetMartínez, 2007). Through the analyses, we observed that one item for emotional stability and one item for openness to experience substantially decreased the observed reliability in both samples. These items include words that are infrequent in Spanish even for a native, and may be distorting the answers. Therefore, we removed these items from the final analyses.

The five factors are listed below along with the observed reliability in our two samples of participants ( $i=$ immigrant, $n=$ native $)$, the number of items comprising 
each dimension, and a sample item: (1) Emotional Stability $\left(\alpha_{\mathrm{i}}=.63, \alpha_{\mathrm{n}}=.68\right), 7$ items, "Is relaxed, handles stress well"; (2) Extraversion $\left(\alpha_{i}=.61, \alpha_{n}=.63\right), 8$ items, "Is talkative"; (3) Openness to Experience ( $\left.\alpha_{i}=.68, \alpha_{n}=.66\right), 9$ items, "Is original, comes up with new ideas"; (4) Agreeableness $\left(\alpha_{i}=.60, \alpha_{n}=.67\right), 9$ items, "Likes to cooperate with others"; and (5) Conscientiousness, $\left(\alpha_{\mathrm{i}}=.58, \alpha_{\mathrm{n}}=.64\right), 9$ items, "Makes plans and follows through with them." The reliability indexes are sufficient for exploratory research except for Conscientiousness in immigrants. Thus, results regarding this trait should be considered with caution.

Attitudes to Safety Scale (Cheyne, Cox, Oliver, \& Tomás, 1998). Perception of safety climate was measured with this instrument, which was previously validated in Spanish (see Tomás, Rodrigo, \& Oliver, 2005). As participants were from different organizations, we removed two dimensions referring to the specific organization of each participant, focusing the analysis only on individual perception of safety climate. The three dimensions are listed below along with the observed reliability, the number of items comprising each dimension, and a sample item: (1) Communication $\left(\alpha_{\mathrm{i}}=.87 ; \alpha_{\mathrm{n}}=\right.$ .87), 5 items, "They showed me how to perform my work safely"; (2) Goals ( $\alpha_{i}=.74 ; \alpha_{n}$ $=.81), 3$ items, "Minor accidents are considered inherent to the work" (reversed); and (3) Individual Responsibility $\left(\alpha_{i}=.63 ; \alpha_{n}=.57\right), 3$ items, "I can influence the safety and health of my company". A confirmatory factor analysis was performed to ensure the dimensionality of perception of safety climate, and the results supported the proposed structure, $\chi^{2}(41)=80.23, p=.000, \mathrm{CFI}=.97, \mathrm{TLI}=.96, \mathrm{RMSEA}=.06, \mathrm{SRMR}=.03$. Spanish version of the General Health Questionnaire - 12 (GHQ-12; Rocha, Pérez, Rodríguez-Sanz, Borrel, \& Obiols, 2011). The observed reliability in our participants was adequate $\left(\alpha_{i}=.76 ; \alpha_{n}=.84\right)$. A sample item is "How often do you feel unhappy and depressed?". 


\section{Procedure}

To collect data, seven public (e.g., vocational schools) and four private organizations (e.g., NGOs, labor unions) that perform counseling, advising, and training services were invited to collaborate. Six public (85.7\%) and three private $(75.0 \%)$ organizations consented to participate. Thus, participants were recruited in a convenience sample as follows: for three months, a member of the research team or a partner who worked in the organization went to the facilities of each collaborating organization and requested potential participants to collaborate. The informed consent of each participant was gathered after they had been informed of the research purposes, the procedures involved in the research, the benefits of the research to society, the length of time the subject was expected to participate, and their rights regarding anonymity of responses, confidentiality ${ }^{1}$, and the possibility to withdraw from the study at will. The questionnaires were given in Spanish to be filled in on the spot. A trained person was present who could clarify any doubts that might arise when completing the questionnaire.

Analysis

Data analyses (chi-square, mean differences, descriptive statistics, reliability, $T$ test, correlations, and regression analysis) were performed with SPSS v22. Missing data were eliminated using listwise deletion. Regarding regression analyses, we calculated one model for immigrants and another one for natives. We followed a hierarchical approach in both models: in the first step, we introduced sociodemographic variables:

\footnotetext{
${ }^{1}$ To ensure confidentiality and promote participation among immigrant workers, we had to reduce the amount of sociodemographic data. This is because the Government was carrying out many deportations at the time the data were collected, and even immigrants with permission to reside in the country were not willing to share their personal data.
} 
age, and years of schooling; in the second step, we introduced the endogenous variables ('Big Five' personality traits); and in the last third step, we introduced the exogenous variables (perception of safety climate dimensions).

\section{Results}

In Table 1, the descriptive statistics, and the differences between immigrant and native workers can be found. Firstly, we analyzed differences between immigrants and natives. The analyses showed that there were no differences in well-being $(t=-0.8, p=$ $.40)$, but there were differences in the predictor variables: immigrants had a higher mean in Emotional Stability $(t=-4.3, p=.001)$, Openness $(t=4.6, p=.001)$, Agreeableness $(t$ $=5.9, p=.001)$, and Conscientiousness $(t=6.7, p=.001)$ than natives. They were no differences in the remaining predictors (Extraversion and the three dimensions of safety climate). It is noteworthy that high Openness and Conscientiousness were related to the 'migrant personality' construct.

\section{[INSERT TABLE 1 ABOUT HERE]}

Descriptive statistics were similar both for immigrants and natives. We also compared the correlations of the variables of the study, observing differences in the associations with well-being depending on the worker's origin. Thus, in accordance with the literature, all the 'Big Five' were associated with well-being, regardless of workers' origin. However, the perception of safety climate showed a differential functioning between immigrants and natives in terms of goals $\left(r_{\mathrm{i}}=.20, p \leq .05 ; r_{\mathrm{n}}=.06\right.$, $p=.44)$ and individual responsibility $\left(r_{\mathrm{i}}=.01, p=.97 ; r_{\mathrm{n}}=.17, p \leq .05\right)$.

To verify our hypotheses and proposals, we performed two hierarchical regression analyses, one for immigrants (Table 2) and another for natives (Table 3). As can be seen, neither predictive model increased their explained variance in Step 3 (i.e., 
when including the perception of safety climate). Thus, the 'Big Five' (Step 2) was sufficient to predict well-being. Therefore, the predictive model for immigrants explained $23 \%$ of the variance and contained Emotional Stability $(\beta=.41, p \leq .000)$ and Extraversion $(\beta=.22, p \leq .01)$ as predictors. Regarding natives, the predictive model explained $37 \%$ of the variance and contained Emotional Stability $(\beta=.37 p \leq .000)$ as the sole predictor. Thus, H1 was partially supported (i.e., not all the 'Big Five' are predictors of well-being), $\mathrm{H} 2$ was supported (i.e., personality plays a different role in the prediction of well-being depending on the origin of the worker), but $\mathrm{H} 3$ and $\mathrm{H} 4$ were not supported (i.e., perception of safety climate is not involved in any predictive model).

[INSERT TABLE 2 ABOUT HERE]

[INSERT TABLE 3ABOUT HERE]

\section{Discussion}

The merging of cultures has led to a more diverse workforce in organizations, which has implications that should be taken into account, especially regarding occupational health. Our study has shown that immigrant and native workers have similarities but also differences in their personal predictors of well-being. Previous literature has offered explanations based on environmental variables (e.g., differences in job status between immigrants and natives) but our study is focused on individual-level variables. Without denying the influence of the environment, workers' personal characteristics should be considered when designing successful preemptive actions. Now, we shall discuss our findings and their implications.

Research has shown that immigrant workers report poorer well-being than natives, but our study did not find substantial differences in this matter. This result may 
be due to the fact that all the immigrants in our sample had a job and had a residence permit (or were in process of obtaining it). Other authors have found similar results in immigrants in Spain in quality of life (Patiño \& Kirchner, 2009).

Regarding the prediction of well-being, immigrant and native workers shared two characteristics: (1) although all the personality variables are related to well-being, only some traits are good predictors; (2) the perception of safety climate does not play a role in the predictive model.

Focusing on personality, emotional stability and extraversion are included in the predictive model, but the latter only for immigrant workers. These results are interesting because, in our study, immigrants reported higher emotional stability but the same level of extraversion as natives. This differential profile supports the proposal of considering immigration as a risk factor, recommending that organizations should develop action plans to facilitate the acculturative process. In this sense, the preference for having a good relationship with peers and supervisors that characterize extraverted workers, like the immigrants' results shown herein, make coworkers with direct relationship with immigrant workers the best way to increase their well-being (e.g., through mentoring programs). However, Ramos-Villagrasa, García-Izquierdo, and García-Izquierdo (2011) have found that native workers tend to choose segregation (i.e., staying away from immigrants and their culture) as their main acculturative strategy at work, making it harder to apply this kind of practices. Moreover, emotional stability and extraversion are the traits that, along with conscientiousness, have a stronger relationship with job performance according to the meta-analysis by Schmidt, Oh, and Schaffer (2016). These results suggest an interesting opportunity for practitioners, because selecting individuals with high values on these traits increases the probability of having a productive and satisfactory workforce at the same time. 
Other remarkable results are related to the perception of safety climate. Our data show differential associations of the diverse dimensions of safety climate as a function of workers' origin: for immigrants, safety-related goals are associated with well-being but, for natives, the associations occur with the remaining dimensions: communication and individual responsibility. Although no dimension is related to well-being, data suggest that immigrants and natives perceive safety climate differently, and these differences may have an impact on other safety outcomes, like workplace accidents. Further research should take this into account.

\section{Limitations and recommendations for further research}

There is no doubt that this study has some limitations that should be addressed. One of them is related to the data and their analysis: data were gathered by self-report and this may produce bias like common method variance. Furthermore, the research design is cross-sectional and does not lead to a complete comprehension of the phenomena investigated. These limitations are usual in industrial and organizational psychology research, especially in studies where there are no prior studies, such as this one. In any event, we propose further research using different research methods and longitudinal designs in order to obtain better results. As an example, a longitudinal study that examines workers before leaving their country may help to explore the nature of the differences in 'migrant personality'.

Another limitation is related to the participants. According to the differences found between immigrants and natives (i.e., in terms of age, years of schooling, and work sector), results suggest that the two samples have some differences that hinder the comparisons and reduce the generalization of the results. For example, it is known that differences in the jobs performed may lead to differences in workers' perceptions. Thus, 
differences between immigrants and natives in this matter may have had an impact on our results. Nevertheless, the study of psychosocial-work issues related to immigration is still scarce, and we believe that our research serves as a first approximation that could be improved with further research, especially in a country where immigration is a new phenomenon (Vallejo-Martín, 2017). In addition, the sample size is also insufficient to divide the immigrant sample into different countries. Studies at country-level and with homogeneous samples could help to increase knowledge about the heterogeneity present amongst immigrant workers.

Regarding future research, we would like to stress that more studies of the relationship between immigration and workplace safety outcomes are needed.

\section{Conclusion}

The migratory movements have led to a new scenario in the organizational setting, where being an immigrant should be considered a risk factor. In the present paper, we have shown some differences related to well-being, suggesting the need for more research of the promotion of healthy work environments for all workers, regardless of their origin. Thus, our role as researchers is to investigate the personal and contextual factors that determine these differences with a view to guiding practitioners in the promotion of safer work environments. 


\section{References}

Benet-Martínez, V., \& John, O. P. (1998). Los Cinco Grandes across cultures and ethnic groups: multitrait multimethod analyses of the Big Five in Spanish and English. Journal of Personality and Social Psychology, 75, 729-750. doi:10.1037/00223514.75.3.729

Bennett, K. M., Scornaiencki, J. M., Brzozowski, J., Denis, S., \& Magalhaes, L. (2012). Immigration and its impact on daily occupations: A scoping review. Occupational Therapy International, 19, 185-203. doi:10.1002/oti.1336

Berry, J. W. (1997). Immigration, acculturation and adaptation. Applied Psychology: An International Review, 46, 5-34. doi:10.1111/j.1464-0597.1997.tb01087.x

Boneva, B. S., \& Frieze, I. H. (2001). Toward a concept of a migrant personality. Journal of Social Issues, 47, 477-491. doi:10.1111/0022-4537.00224

Cheyne, A., Cox, S., Oliver, A., \& Tomás, J. M. (1998). Modelling safety climate in the prediction of levels of safety activity. Work \& Stress, 12, 255-271. doi:10.1080/02678379808256865

Christian, M. S., Bradley, J. C., Wallace, J. C., \& Burke, M. J. (2009). Workplace safety: A meta-analysis of the roles of person and situation factors. Journal of Applied Psychology, 94, 1103-1127. doi:10.1037/a0016172.

Dalgard, O. S., Thapa, S. B., Hauff, E., McCubbin, M., \& Syed, H. R. (2006). Immigration, lack of control and psychological distress: Findings from the Oslo Health Study. Scandinavian Journal of Psychology, 47, 551-558.

doi:10.1111/j.1467-9450.2006.00546.x 
Diener, E., Oishi, S., \& Lucas, R. E. (2003). Personality, culture, and subjective wellbeing: Emotional and cognitive evaluations of life. Annual Review of Psychology, 54, 403-425. doi:10.1146/annurev.psych.54.101601.145056

Dollard, M. F., \& Bakker, A. B. (2010). Psychosocial safety climate as a precursor to conducive work environments, psychological health problems, and employee engagement. Journal of Occupational and Organizational Psychology, 83, 579599. doi:10.1348/096317909X470690

Guldenmund, F., Cleal, B., \& Mearns, K. (2013). An exploratory study of migrant workers and safety in three European countries. Safety Science, 52, 92-99. doi:10.1016/j.ssci.2012.05.004

Hoppe, A. (2011). Psychosocial working conditions and well-being among immigrant and German low-wage workers. Journal of Occupational Health Psychology, 16, 187-201. doi:10.1037/a0021728

Idris, M. A., Dollard, M. F., Coward, J., \& Dormann, C. (2012). Psychosocial safety climate: Conceptual distinctiveness and effect on job demands and worker psychological health. Safety Science, 50, 19-28. doi:10.1016/j.ssci.2011.06.005

Janssens, M., Brett, J., \& Smith, F. J. (1995). Confirmatory cross-cultural research: Testing the viability of a corporation-wide safety policy. Academy of Management Journal, 38, 364-382. doi:10.2307/256684

McCrae, R. R., \& Terracciano, A. (2005). Universal features of personality traits from the observer's perspective: Data from 50 cultures. Journal of Personality and Social Psychology, 88, 547-561. doi:10.1037/0022-3514.88.3.547

Patiño, C., \& Kirchner, T. (2009). Estrés y calidad de vida en inmigrantes latinoamericanos en Barcelona [Stress and quality of life in LatinAmerican immigrants in Barcelona]. Ansiedad y Estrés, 15, 49-66. 
Polek, E., Van Oudenhoven, J. P. V., \& Ten Berge, J. M. F. (2011). Evidence for a "Migrant Personality": Attachment styles of Poles in Poland and Polish immigrants in the Netherlands. Journal of Immigration \& Refugee Studies, 9, 311-326. doi:1080/15562948.2011.616163

Ramos-Villagrasa, P. J., García-Izquierdo, A. L., \& García-Izquierdo, M. (2011). Acculturative strategies and emotional exhaustion: Differences between immigrant and national workers in Spain. Ansiedad y Estrés, 17, 63-74.

Ramos-Villagrasa, P. J., García-Izquierdo, A. L., \& Navarro, J. (2013). Predicting the dynamic criteria of basketball players: The influence of the 'Big Five', job experience, and motivation. Journal of Work and Organizational Psychology, 29, 29-35. doi:10.5093/tr2013a5

Rocha, K. B., Pérez, K., Rodríguez-Sanz, M., Borrel, C., \& Obiols, J. E. (2011). Propiedades psicométricas y valores normativos del General Health Questionnaire (GHQ-12) en población general española [Psychometric properties and normative values of General Healt Questionnaire (GHQ-12) in Spanish general population]. International Journal of Clinical and Health Psychology, 11, 125-139.

Schenker, M. B. (2010). A global perspective of migration and occupational health. American Journal of Industrial Medicine, 53, 329-337. doi:10.1002/ajim.20834

Schmidt, F. L., Oh, I., \& Shaffer, J. A. (2016). The validity and utility of selection methods in personnel psychology: Practical and theoretical implications of 100 years of research findings. Retrieved from https://papers.ssrn.com/sol3/papers.cfm?abstract_id=2853669

Schmitt, D. P., Allik, J., McCrae, R. R., \& Benet-Martínez, V. (2007). The geographic distribution of Big Five personality traits: Patterns and profiles of human self- 
description acrros 56 nations. Journal of Cross-Cultural Psychology, 38, 173212. doi: $10.1177 / 0022022106297299$

Steel, P., Schmidt, J., \& Shultz, J. (2008). Refining the relationship between personality and subjective well-being. Psychological Bulletin, 134, 138-161. doi:10.1037/003 3-2909.134.1.138

Tabor, A. S., Milfont, T. L., \& Waard, C. (2015). The migrant personality revisited: Individual differences and international mobility intentions. New Zealand Journal of Psychology, 44, 89-95.

Tomás, J. M., Rodrigo, M. F., \& Oliver, A. (2005). Modelos lineales y no lineales en la explicación de la siniestralidad laboral [Linear and nonlinear models explaining occupational safety]. Psicothema, 17, 154-163.

Vallejo-Martín, M. (2017). Una aproximación al síndrome de burnout y las características laborales de emigrantes espanoles en países europeos [An approach to burnout and job characteristics of Spanish emigrants in European countries]. Journal of Work and Organizational Psychology, 33, 137-145. doi:10.1016/j.rpto.2017.02.001

Vallejo-Martín, M., \& Moreno-Jiménez, P. (2014). Del culturalismo al bienestar psicológico: Propuesta de un modelo de satisfacción vital en el proceso de aculturación de inmigrantes [From culturalism to psychological well-being: A model of satisfaction with life through immigrants' acculturative process]. Boletín de Psicología, 110, 53-67.

Yakhnich, L. (2008). Immigration as a multiple-stressor situation: Stress and coping among immigrants from the former Soviet Union in Israel. International Journal of Stress Management, 15, 252-268. doi:10.1037/a0013002 
Zohar, D. (1980). Safety climate in industrial organizations: Theoretical and applied implications. Journal of Applied Psychology, 65, 96-102. doi:10.1037/00219010.65 .1 .96 


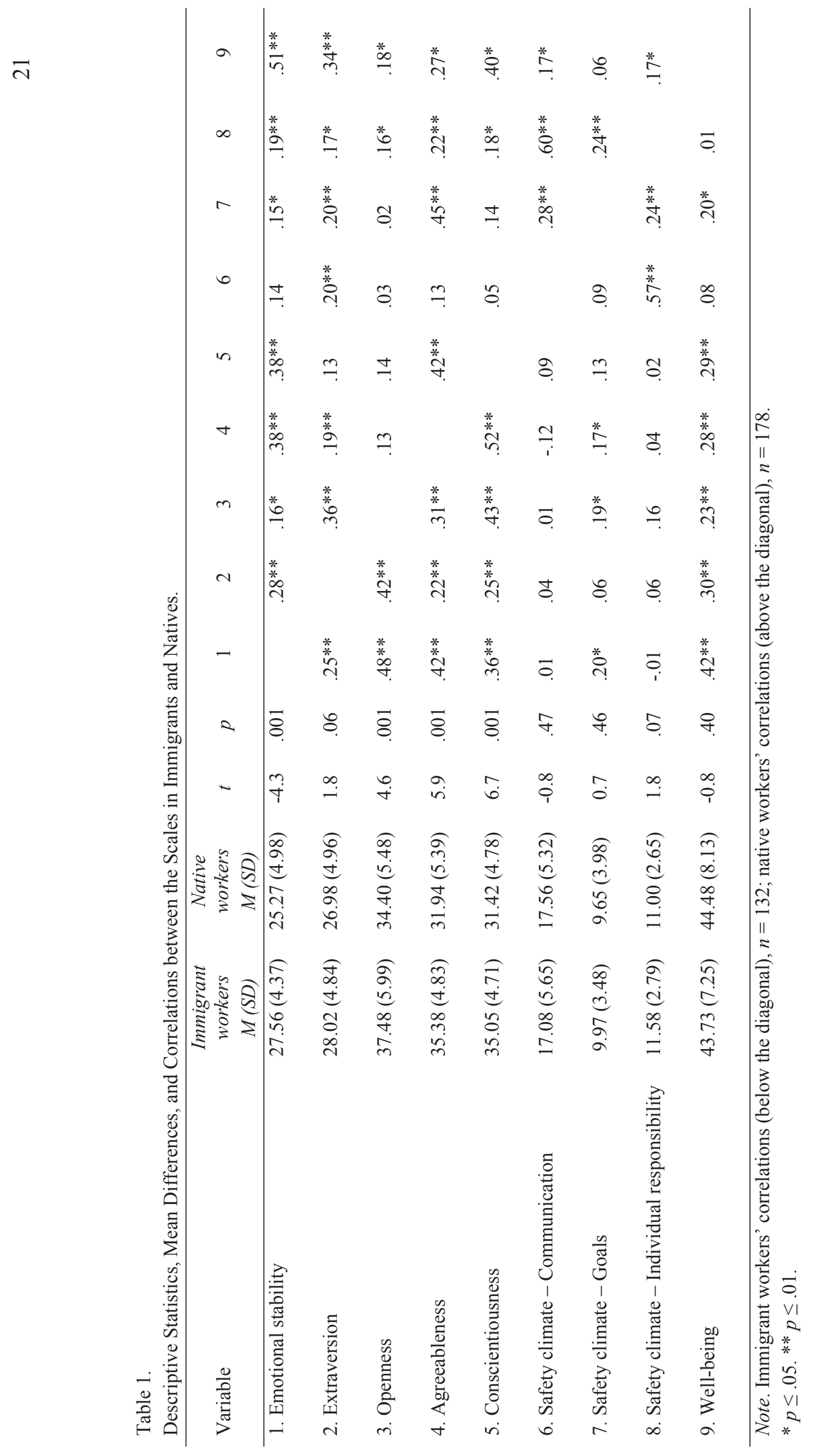


Table 2.

Predictive models of well-being for immigrants.

\begin{tabular}{|c|c|c|c|c|c|c|c|c|}
\hline Step & Predictors & $B$ & $95 \% \mathrm{CI}$ & $p$ & $R^{2}$ & $\Delta R^{2}$ & $R^{2}{ }_{a d j}$ & $\Delta R_{a d j}^{2}$ \\
\hline \multirow[t]{3}{*}{1} & Sex & -.17 & {$[-5.48,0.06]$} & .05 & .02 & & .03 & \\
\hline & Age & .13 & {$[-0.03,0.25]$} & .12 & & & & \\
\hline & Years of schooling & .04 & {$[-0.19,0.33]$} & .59 & & & & \\
\hline \multirow[t]{8}{*}{2} & Sex & -.07 & {$[-3.54,1.20]$} & .33 & .28 & .26 & .23 & .20 \\
\hline & Age & .01 & {$[-0.13,0.12]$} & .95 & & & & \\
\hline & Years of schooling & .09 & {$[-0.08,0.39]$} & .19 & & & & \\
\hline & Emotional stability & .41 & {$[0.04,0.79]$} & .000 & & & & \\
\hline & Extraversion & .22 & {$[0.12,0.61]$} & .004 & & & & \\
\hline & Openness & .05 & {$[-0.12,0.28]$} & .44 & & & & \\
\hline & Agreeableness & .01 & {$[-0.25,0.26]$} & .99 & & & & \\
\hline & Conscientiousness & .15 & {$[-0.02,0.52]$} & .07 & & & & \\
\hline \multirow[t]{11}{*}{3} & Sex & -.09 & {$[-3.94,0.93]$} & .22 & .31 & .03 & .24 & .01 \\
\hline & Age & .01 & {$[-0.13,0.13]$} & .99 & & & & \\
\hline & Years of schooling & .11 & {$[-0.06,0.43]$} & .13 & & & & \\
\hline & Emotional stability & .41 & {$[0.01,-0.74]$} & .000 & & & & \\
\hline & Extraversion & .20 & {$[-0.08,0.59]$} & .01 & & & & \\
\hline & Openness & .06 & {$[-0.12,0.29]$} & .42 & & & & \\
\hline & Agreeableness & .01 & {$[-0.28,0.28]$} & .99 & & & & \\
\hline & Conscientiousness & .13 & {$[-0.05,0.51]$} & .10 & & & & \\
\hline & Safety climate - Communication & .07 & {$[-0.15,0.38]$} & .39 & & & & \\
\hline & Safety climate - Goals & -.01 & {$[-0.34,0.30]$} & .89 & & & & \\
\hline & $\begin{array}{l}\text { Safety climate - Individual } \\
\text { responsibility }\end{array}$ & .04 & {$[-0.41,0.63]$} & .66 & & & & \\
\hline
\end{tabular}

Note. Cohen's f $2=0.39$. 
Table 3.

Predictive models of well-being for natives.

\begin{tabular}{|c|c|c|c|c|c|c|c|c|}
\hline Step & Predictors & B & $95 \% \mathrm{CI}$ & $p$ & $R^{2}$ & $\Delta R^{2}$ & $R_{a d j}^{2}$ & $\Delta R^{2}{ }_{a d j}$ \\
\hline \multirow[t]{3}{*}{1} & Sex & -.10 & {$[-4.16,1.19]$} & .27 & .06 & & .04 & \\
\hline & Age & .04 & {$[-0.11,0.16]$} & .68 & & & & \\
\hline & Years of schooling & -.06 & {$[-0.37,0.19]$} & .54 & & & & \\
\hline \multirow[t]{8}{*}{2} & Sex & -.01 & {$[-2.77,2.48]$} & .91 & .40 & .34 & .37 & .20 \\
\hline & Age & .03 & {$[-0.10,0.14]$} & .75 & & & & \\
\hline & Years of schooling & -.07 & {$[-0.37,0.16]$} & .43 & & & & \\
\hline & Emotional stability & .35 & {$[0.33,0.94]$} & .000 & & & & \\
\hline & Extraversion & .17 & {$[-0.02,0.54]$} & .07 & & & & \\
\hline & Openness & -.04 & {$[-0.32,0.22]$} & .72 & & & & \\
\hline & Agreeableness & .06 & {$[-0.21,0.39]$} & .56 & & & & \\
\hline & Conscientiousness & .15 & {$[-0.07,0.57]$} & 12 & & & & \\
\hline \multirow[t]{11}{*}{3} & Sex & .01 & {$[-2.48,2.81]$} & .91 & .41 & .01 & .36 & .01 \\
\hline & Age & .01 & {$[-0.11,0.13]$} & .89 & & & & \\
\hline & Years of schooling & -.08 & {$[-0.40,0.15]$} & .34 & & & & \\
\hline & Emotional stability & .32 & {$[0.31,0.93]$} & .002 & & & & \\
\hline & Extraversion & .17 & {$[-0.12,0.54]$} & .06 & & & & \\
\hline & Openness & -.04 & {$[-0.33,0.22]$} & .06 & & & & \\
\hline & Agreeableness & .07 & {$[-0.19,0.41]$} & .47 & & & & \\
\hline & Conscientiousness & .16 & {$[-0.05,0.58]$} & .10 & & & & \\
\hline & Safety climate-Communication & .16 & {$[-0.04,0.46]$} & .11 & & & & \\
\hline & Safety climate - Goals & .14 & {$[-0.06,0.66]$} & .09 & & & & \\
\hline & $\begin{array}{l}\text { Safety climate - Individual } \\
\text { responsibility }\end{array}$ & -.11 & {$[-0.86,0.25]$} & .29 & & & & \\
\hline
\end{tabular}

Note. Cohen's $\mathrm{f} 2=0.67$. 